\title{
Perception of asthma symptoms
}

\author{
Percepção de sintomas na asma
}

\section{Alberto Cukier}

A 32-year-old female patient sought emergency room treatment for severe pain occurring at the level of the shoulder blades and radiating to the sternal region. The patient had a history of asthma, which had become intermittent over the previous years. For three months, due to adverse environmental conditions at her place of work, she had been using short-acting $\beta_{2}$ agonists three times a week for symptom relief. The chest X-ray findings were normal. The patient was treated with analgesics and antiinflammatory agents. Because her condition persisted, she returned to the hospital $48 \mathrm{~h}$ later, and the process was repeated. Six days after the onset of the chest pain, the patient again sought treatment. She told the physician that, during her childhood and adolescence, when the asthma attacks were frequent, her mother had told her that the chest pains were a sign of asthma exacerbation. Physical examination revealed normal respiration, without adventitious sounds. Spirometry findings were indicative of obstructive lung disease, with an FEV of 37\% of predicted and bronchodilator reversibility of $70 \%$. This case, which is uncommon and real, reflects well the complexity involving what asthma patients feel, how such patients express themselves about the disease, and how health professionals interpret the complaints of such patients.

It has long been known that the relationship between symptoms and objective measures of lung function is poor. In a classic study conducted 40 years ago, McFadden et al. correlated pulmonary mechanics with the symptoms and physical examination findings of 22 patients, during attacks of bronchospasm and, serially, during treatment. ${ }^{(1)}$ The authors observed that patients with functional limitation that was more severe could not be identified on the basis of the degree of dyspnea and wheezing, as well as that, regardless of the initial degree of bronchospasm, when the patients became asymptomatic, the parameters of lung mechanics remained at $40-50 \%$ of predicted..$^{(1)}$ Recognition of the dissociation between clinical and functional data is evident in the current strategy adopted for asthma management, which uses a composite score in order to determine when the disease is controlled. ${ }^{(2)}$ The guidelines have adopted this concept based on the observation that outcomes, such as symptoms, use of rescue medication, or spirometric parameters, when evaluated in isolation, inaccurately reflect asthma patient response to treatment. ${ }^{(3)}$

The discrepancy between subjective (patientreported) symptoms and objective measures of lung function has been studied by various methods, most of which classify patients as "underperceivers" or "overperceivers". Estimates of the magnitude of the disparity vary widely, the reported prevalence of underperception ranging from $15 \%$ to $60 \%$, which demonstrates how little is known about the subject.

The literature has given particular emphasis to the proportion of patients considered to be underperceivers-those who would be unable to evaluate the severity of their situation accurately and would therefore be at increased risk of hospitalization and morbidity, because they postpone seeking appropriate treatment. In this issue of the Brazilian Journal of Pulmonology, Reck et al. analyzed this facet in a study involving 53 patients with mild asthma. ${ }^{(4)}$ Of those 53 patients, 21 (39\%) were unable to identify methacholine-induced bronchoconstriction. In another study conducted in Brazil, patientreported asthma symptoms (evaluated by a visual analog scale) were compared with spirometric data, and the authors concluded that $51 \%$ of the patients did not accurately characterize the degree of airway obstruction..$^{(5)}$ In contrast, there are some asthma patients who tend to be quite sensitive to small changes in airway caliber, which would lead them to overmedicate themselves, with excessive use of bronchodilators for symptom relief.(6) Therefore, we appear to have an airtight case: asthma patients are divided into "normal perceivers", overperceivers, and underperceivers. Underperceivers would 
be subject to increased morbidity and mortality, whereas overperceivers would tend to overuse medication. Underperceivers and overperceivers would be candidates for low adherence to treatment regimens, due to either undermedication or overmedication. Does this division actually make sense?

In my opinion, psychological sciences make an important contribution, as evidenced by what we see in clinical practice. According to one group of authors, a small proportion of asthma patients have trait-like stability in terms of how accurately they report their symptoms (whether their perception is in agreement or disagreement with the severity of their actual clinical status). ${ }^{(7)}$ It is likely that such individuals have permanent impairment of the central processing of signals from the neurobiological pathways. Unlike that small group, most asthma patients are inconsistent in their perception ability, which is strongly influenced by expectations and emotional factors that interact with the personality and the context of current situations. ${ }^{(7)}$ In support of this theory, there have been studies suggesting that different triggering factors (such as exercise or nonspecific bronchial challenge) generate various sensations, ${ }^{(8)}$ as do the high levels of anxiety and depression to which such patients are subject..$^{(9)}$ In conclusion, as exemplified by the clinical case described, the language of asthma symptoms is complex and poorly elucidated. This situation underscores the importance of an objective assessment of lung function, especially in patients with asthma that is more unstable and more severe. We should redouble our efforts to listen to such patients, understand their expectations, and identify how they express their discomfort, counseling them appropriately.

\author{
Alberto Cukier \\ Tenured Professor of Pulmonology \\ Department of Pulmonology, \\ Heart Institute, \\ University of São Paulo School of \\ Medicine Hospital das Clínicas, \\ São Paulo, Brazil
}

\section{References}

1. McFadden ER Jr, Kiser R, DeGroot WJ. Acute bronchial asthma. Relations between clinical and physiologic manifestations. N Engl J Med. 1973;288(5):221-5.

2. Sociedade Brasileira de Pneumologia e Tisiologia. IV Diretrizes Brasileiras para o Manejo da Asma. J Bras Pneumol. 2006;32(Suppl 7):S447-S474.

3. Bateman ED, Bousquet J, Braunstein GL. Is overall asthma control being achieved? A hypothesis-generating study. Eur Respir J. 2001;17(4):589-95.

4. Reck CL, Fiterman-Molinari D, Barreto SS, Fiterman J. Poor perception of dyspnea following methacholine challenge test in patients with asthma. J Bras Pneumol. 2010;36(5):539-44.

5. Souza-Machado A, Cavalcanti MN, Cruz AA. Má percepção da limitação aos fluxos aéreos em pacientes com asma moderada a grave. J Pneumol. 2001;27(4):185-92.

6. Mawhinney H, Spector SL, Heitjan D, Kinsman RA, Dirks JF, Pines 1. As-needed medication use in asthma usage patterns and patient characteristics. J Asthma. 1993;30(1):61-71.

7. Janssens T, Verleden G, De Peuter S, Van Diest I, Van den Bergh 0. Inaccurate perception of asthma symptoms: a cognitive-affective framework and implications for asthma treatment. Clin Psychol Rev. 2009;29(4):317-27.

8. Scano G, Stendardi L. Dyspnea and asthma. Curr Opin Pulm Med. 2006;12(1):18-22.

9. Carvalho NS, Ribeiro PR, Ribeiro M, Nunes Mdo P, Cukier A, Stelmach R. Comparing asthma and chronic obstructive pulmonary disease in terms of symptoms of anxiety and depression. J Bras Pneumol. 2007;33(1):1-6. 